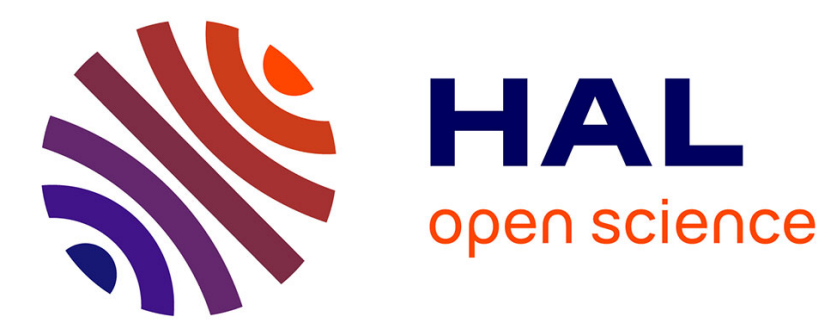

\title{
Modelling for Service Solution of a Closed-Loop Supply Chain with the Presence of Third Party Logistics
}

\author{
Mitali Sarkar, Rekha Guchhait, Biswajit Sarkar
}

\section{To cite this version:}

Mitali Sarkar, Rekha Guchhait, Biswajit Sarkar. Modelling for Service Solution of a Closed-Loop Supply Chain with the Presence of Third Party Logistics. IFIP International Conference on Advances in Production Management Systems (APMS), Aug 2018, Seoul, South Korea. pp.320-327, 10.1007/978-3-319-99704-9_39. hal-02164889

\section{HAL Id: hal-02164889 \\ https://hal.inria.fr/hal-02164889}

Submitted on 25 Jun 2019

HAL is a multi-disciplinary open access archive for the deposit and dissemination of scientific research documents, whether they are published or not. The documents may come from teaching and research institutions in France or abroad, or from public or private research centers.
L'archive ouverte pluridisciplinaire HAL, est destinée au dépôt et à la diffusion de documents scientifiques de niveau recherche, publiés ou non, émanant des établissements d'enseignement et de recherche français ou étrangers, des laboratoires publics ou privés. 


\title{
Modelling for service solution of a closed-loop supply chain with the presence of third party logistics
}

\author{
Mitali Sarkar ${ }^{10000-0002-4549-3035]}$, Rekha Guchhait ${ }^{10000-0002-6839-3360]}$ and Biswajit \\ Sarkar ${ }^{1[0000-0002-6583-8416]}$ \\ ${ }^{1}$ Department of Industrial \& Management Engineering, Hanyang University, Ansan, \\ Gyeonggi-do, 15588, South Korea \\ bsbiswajitsarkar@gmail.com
}

\begin{abstract}
Service, the word itself is a big issue in the corporate world. One of the most important parts of the reputation of a company depends how much it can provide service to customers. It is very difficult to maintain especially when it is related to a closed-loop supply chain. Quality of products is also a main factor of business that is known to all. In this model, a closed-loop supply chain with multi-retailer, single-manufacturer and single- third-party collector (3PL) is considered where service and quality issues are maintained throughout the supply chain. The model is solved by a classical optimization method and obtains global solutions in closed and quasi-closed forms. Numerical experiments are done to illustrate the model clearly. Numerical results prove the reality of the model.
\end{abstract}

Keywords: Closed-loop supply chain, Service, Quality, 3PL, Returned products.

\section{Introduction}

Service is an essential ingredient for business in any supply chain nowadays. Each customer thinks about the good service from any company. If the service is very good in terms of some offers like more products, free gifts, or, discounted prices. There are different studies in this direction. Several authors found major relations within some closed-loop supply chains. Lee [1] worked on different service levels on inventory model. Krishnamoorthy and Viswanath [2] discussed a stochastic production inventory model under service time. Gzara et al. [3] developed a location-allocation model where service is given only for logistic cases. Chen et al. [4] formulated an inventory model for substitutable products and customer's service with objectives. Wheatley et al. [5] worked with service constraints for inventory-location model. Protopappa et al. [6] discussed multiple service levels for two-period inventory allocation problem. Cordes and Hellingrath [7] formulated a master model for service in personal capacity planning with integrated inventory and transport. Marand et al. [8] discussed a service-inventory model for pricing policy. Rahimi et al. [9] formulated a multi-objective stochastic inventory model with service level. This study proposes that in a three-echelon supply chain, service is given by manufacturer to the retailer and retailer gives the same service to their customers. 
As service depends upon price, thus demand is assumed as variable and depends upon price. Also, price is assumed as variable and depend on service. Aydinliyim et al. [10] worked on an inventory model, where products are retailed through online. Transchel [11] discussed an inventory model under two scenarios: price-based substitution and stock-out-based substitution. Wu et al. [12] developed an inventory model for a fixed life-cycled product, where selling price depends upon life expire date. Chen et al. [13] formulated a newsvendor model for multi-period and found an optimal pricing policy for selling. This study proposed a variable selling price with a maximum and a minimum range of selling price and depends upon service also.

To connect the traditional supply chain system to a green supply chain, waste management is under consideration in this proposed model. Rajesh et al. [14] discussed the involvement of third party logistics (3PL) system in India. Li et al. [15] developed a supply chain model under fuzzy environment where 3PL is a supplier. Zhang et al. [16] worked on a dynamic pricing policy for 3PL for heterogeneous type of customers. Huo et al. [17] worked on a supply chain system for a specific asset along with 3PL system under environment uncertainty from an economic perspective. Chung [18] invested the safety stock and lead time uncertainties for supply chain management in a certain situation of international presence. This study proposed a 3PL system for waste management and reuse of products through remanufacturing such that the use of raw materials can be diminished.

\section{$2 \quad$ Problem definition and model formulation}

This section consists of the definition of the research problem and formulation of the research model.

\subsection{Problem Definition}

Recently, an industry, situated at West Bengal, India, is suffering from service issues. The aim of the research is to solve those issues related to the industry. If one can model their whole system, then it looks like a supply chain model with multi-retailer, singlemanufacturer and single-third party. The main issues of the industry are not business flow issue only. The main issues of the industry are how to manage maximum service for the customer with minimum total cost. As quality of products and quality improvement of products are also another big issues; thus, the industry would like to solve their problems globally. It means that they should reach the global optimum solution with optimum lot size, quality, service, service price, service integrator price.

\subsection{Model Formulation}

A homogeneous-power three-echelon supply chain is considered here under third party logistic (3PL). Industry consists of three pillars of strengths as a single-manufacturer, a single-third party, and multi-retailer. The demand of the manufacturer for the industry is $d=\sum_{i=1}^{n} D_{i}=\sum_{i=1}^{n} D\left(\alpha_{i}, \beta_{i}, \theta_{i}\right)=\sum_{i=1}^{n} a_{i} \frac{\left(\alpha_{i}+\beta_{i}\right)_{\max }-\left(\alpha_{i}+\beta_{i}\right)}{\left(\alpha_{i}+\beta_{i}\right)-\left(\alpha_{i}+\beta_{i}\right)_{\min }}+c_{i} \theta^{\delta}{ }_{i}$, where $a_{i}$ and $c_{i}$ are the scaling parameters for price sensitivity and service issues, $\alpha_{i}$ is the selling price of manufacturer, $\beta_{i}$ is the increasing cost related to the service, $\theta_{i}$ is the service 
provided by the manufacturer to the customer, $\delta$ is the service parameter, for retailer $i$. $D_{i}$ is the demand for retailer $i$.

Model of Manufacturer. After completion of production, delivery is started to retailer with single shipment per cycle [19]. Manufacturer has some investments $e$ for service. Both, the manufactured and remanufactured products are maintained the quality $\kappa$, where $0<\kappa<1$. Customers buy any product within those products with same price [20]. Reusable products are collected a rate of $\tau$ of demand of customer by the 3PL, where $\tau$ is a random variable follows uniform distribution. The quality of collected products are considered as $(\mu)$, where $0<\mu<\kappa$. The quality is upgraded during remanufacturing.

Manufacturer faces a variable demand depends upon selling price and given service. He gives service to the retailer such that whenever the retailer sells that product to the customer, they give the same service towards customers. $Q$ is the production lotsize per cycle of the manufacturer, where $\left(Q=\sum_{i=1}^{n} q_{i}\right)$ (units/production cycle). $\mathrm{P}$ is the production rate of manufacturer. The decision variables related to the manufacturer's model is $\alpha_{i}, \beta_{i}, \theta_{i}, q_{i}$. Other costs are given by the following equations as service provider cost, revenue, ordering cost, setup cost, holding cost, raw material cost, remanufacturing cost, quality improvement cost, goodwill lost cost, and, transportation cost of manufacturer. Though, the quality of product is maintaining by the manufacturing system but, yet the quality may not be perfect as demanded by customers. Thus, the manufacturing system may lose its goodwill. The average profit of manufacturer is as follows:

$$
\begin{aligned}
& A P R_{M}\left(\alpha_{i}, \beta_{i}, \theta_{i}, q_{i}\right)=\sum_{i=1}^{n}\left(\alpha_{i}+\beta_{i}\right) D_{i}+h_{u} \tau d\left(1-\frac{d}{2 P}\right)-\left(\frac{\mathrm{e}^{2}}{2}+\frac{o_{m}}{Q}+\frac{s}{Q}+\right. \\
& \left.C_{m}(1-\tau)+\tau\left(C_{r}+C_{3}\right)+C_{q} \kappa^{2}(1-\tau)+\tau C_{q}\left(\kappa^{2}-\mu^{2}\right)\right) d-h_{f}\left[\frac{Q[d+2 P]}{2 P}-\right. \\
& \left.\sum_{i=1}^{n} l_{i} \sum_{j=1}^{i} D_{j}\right]-(1-\kappa) g-C_{t} \sum_{i=1}^{n} l_{i m}\left(\frac{q_{i}}{\varepsilon}\right)
\end{aligned}
$$

where $e$ is the service investment, setup cost per setup is $S$. Manufacturer sales each product with selling price $\alpha_{i}$ and an increasing price $\beta_{i}$ due to service for each retailer. In the manufacturing house raw materials and finished products have to hold for sometimes. $h_{f}$ is holding cost for finished products per unit per unit time and $h_{u}$ is for used products of the manufacturer. Raw material cost for manufacturer is $C_{m}, C_{r}$ is for remanufacturing, and $C_{3}$ average collection costper product. $C_{q}$ is the quality improvement cost. $O_{m}$ is ordering cost of manufacturer for $3 \mathrm{PL}, g$ is goodwill lost cost, and $C_{t}$ is the transportation cost per container per unit distance.

Model of Retailer. Retailer takes the service from the manufacturer and gives the same service to their customers. Used products are taken by 3PL, which are recycled and remanufactured. Retailer's demand $\left(D^{\prime}{ }_{i}=D^{\prime}\left(\alpha^{\prime}{ }_{i}, \beta_{i}, \theta_{i}\right)=a_{i} \frac{\left(\alpha^{\prime}{ }_{i}+\beta_{i}\right)_{\max }-\left(\alpha^{\prime}{ }_{i}+\beta_{i}\right)}{\left(\alpha^{\prime}{ }_{i}+\beta_{i}\right)-\left(\alpha^{\prime}{ }_{i}+\beta_{i}\right)_{\min }}+\right.$ $\left.c_{i} \theta^{\delta_{i}}{ }_{i}\right)$ due to customer is given by the expression where $\alpha^{\prime}{ }_{i}$ is the selling price of retailer $i . q_{i}$ is the lot size quantity for each retailer $i . Z$ is the shipment schedule of the retailers $i$. From this shipment schedule, manufacturer can decide which retailer among 
$n$ should replenish first. The values of $Z$ depend on the demand of the retailer and lead time of the retailer. The expression for $Z$ is $Z=\frac{D^{\prime}}{l_{i}}$. The decision variables related to the retailer's model is $Z, \alpha^{\prime}{ }_{i}, q_{i}$. Other costs of the retailer $i$ are revenue, ordering cost, and holding cost. The selling price of each retailer is $\alpha_{i}{ }^{\prime}$. Ordering cost of retailer $i$ is $A_{i}$ per order. $h_{i}$ is the holding cost of retailer. The average profit of retailer $i$ is

$$
A P R_{R}\left(Z, \alpha^{\prime}{ }_{i}, q_{i}\right)=\sum_{i=1}^{n}\left(\alpha^{\prime}{ }_{i}+\beta_{i}\right) D^{\prime}{ }_{i}-\sum_{i=1}^{n} \frac{A_{i} D^{\prime}{ }_{i}}{q_{i}}-\sum_{i=1}^{n} \frac{h_{i} q_{i}}{2}
$$

Model of Third Party Logistics. Demand of 3PL is governed by retailers. Total demand for $3 \mathrm{PL}$ is given by $D=\sum_{i=1}^{n} D^{\prime}{ }_{i}$. Through third party, used products are collected from retailers and after recycling and remanufacturing it is forwarded to manufacturer. The costs related to the 3PL are as follows: revenue, transportation cost, container management cost, setup cost, collection and recycling cost, holding cost for products, investment for used product, and purchasing. The decision variables related to the 3PL's model is $\tau, q_{i}, \alpha$. Average profit of third party is given by the following expression

$$
\begin{gathered}
A P R_{P}\left(\tau, q_{i}, \alpha\right)=\left(C_{3} \tau-\frac{S}{Q}-\frac{S_{3}}{Q}-\tau R_{c}-\frac{\tau h_{u}}{2}\right) D-C_{t}\left[\sum_{i=1}^{n} l_{i k}\left(\frac{q_{i}}{\varepsilon}\right)+l_{k m}\left(\frac{D \tau}{\varepsilon}\right)\right]- \\
C_{\alpha} \varepsilon^{s-1} D_{\max } \frac{Q}{D}-h_{r}\left(\sum_{i=1}^{n} l_{i}\left(\frac{D_{\max }-D_{i}}{\varepsilon}\right)+\left(\frac{Q}{D}-\sum_{i=1}^{n} l_{i}\right) \frac{D_{\max }}{\varepsilon}\right)+\gamma \tau^{2}
\end{gathered}
$$

The number of required containers for a single shipment to retailer $i$ is $q_{i} / \varepsilon$, where $\varepsilon$ is the capacity of single container. $l_{i}$ is the lead time of retailer $i$, i.e. time between delivery to retailer $i$ and $i+1$. Distances between retailer $i-3 \mathrm{PL}$ is $l_{i k}$, and 3PL - manufacturer is $l_{k m}, R_{c}$ is average recycling cost collected by the 3PL, $S_{3}$ is the setup cost per setup for collecting EOL/EOU products at 3PL, $\gamma$ is effective investment by 3PL to collects EOL/EOU products. Minimum number of containers $r_{i}=\left\lceil\frac{q_{\max }}{\varepsilon}\right\rceil$. Hence, it is assumed that the maximum number of containers in the system is $\left\lceil\frac{q_{\max }}{\varepsilon}\right\rceil$ in order to minimize the management and holding costs of containers such that $\tau_{\max }=\left\lceil\frac{D_{\max } T}{\varepsilon}\right\rceil$ (for instance see [19]), $D_{\max }$ maximum demand rate at the retailers. The cost of managing containers is $C_{\alpha}, s$ is scaling factor and it gives the relationship between a container size and management costs, For values $s>1$, the management of a large container is expensive compare to smaller one and for $s<1$ the management of a large container is cheaper than small container.

Therefore, the total profit of the supply chain is given by the expression

$$
\begin{gathered}
T P\left(Z, \alpha_{i}, \alpha^{\prime}{ }_{i}, \beta_{i}, \theta_{i}, q_{i}, \tau, \varepsilon\right)=A P R_{M}\left(\alpha_{i}, \beta_{i}, \theta_{i}, q_{i}\right)+A P R_{R}\left(\alpha^{\prime}{ }_{i}, q_{i}\right)+A P R_{P}\left(\tau, q_{i}, \varepsilon\right) \\
=\sum_{i=1}^{n}\left(\alpha_{i}+\beta_{i}\right) D_{i}-\left(\frac{\mathrm{e}^{2}}{2}+\frac{o_{m}}{Q}+\frac{S}{Q}+C_{m}(1-\tau)+\tau\left(C_{r}+C_{3}\right)+C_{q} \kappa^{2}(1-\tau)+\right. \\
\left.\tau C_{q}\left(\kappa^{2}-\mu^{2}\right)-h_{u} \tau\left(1-\frac{d}{2 P}\right)\right) d-h_{f}\left[\frac{Q[d+2 P]}{2 P}-\sum_{i=1}^{n} l_{i} \sum_{j=1}^{i} D_{j}\right]-(1-\kappa) g- \\
C_{t} \sum_{i=1}^{n} l_{i m}\left(\frac{q_{i}}{\varepsilon}\right)+\sum_{i=1}^{n}\left(\alpha^{\prime}{ }_{i}+\beta_{i}\right) D^{\prime}{ }_{i}-\sum_{i=1}^{n} \frac{A_{i} D^{\prime}{ }_{i}}{q_{i}}-\sum_{i=1}^{n} \frac{h_{i} q_{i}}{2}+\left(C_{3} \tau-\frac{S}{Q}-\frac{S_{3}}{Q}-\right. \\
\left.\tau R_{c}-\frac{\tau h_{u}}{2}\right) D-C_{t}\left[\sum_{i=1}^{n} l_{i k}\left(\frac{q_{i}}{\varepsilon}\right)+l_{k m}\left(\frac{D \tau}{\varepsilon}\right)\right]-C_{\alpha} \varepsilon^{s-1} D_{\max } \frac{Q}{D}- \\
h_{r}\left[\sum_{i=1}^{n} l_{i}\left(\frac{D_{\max }-D_{i}}{\varepsilon}\right)+\left(\frac{Q}{D}-\sum_{i=1}^{n} l_{i}\right) \frac{D_{\max }}{\varepsilon}\right]+\gamma \tau^{2}
\end{gathered}
$$


The optimum values of the decision variables are found by using classical optimization techniques and finally test Hessian matrix to test the optimality condition.

\section{$3 \quad$ Numerical Example}

Numerical example gives a numerical result regarding this theoretical model. Data is taken from industry visit and Table 1 gives the input data for this numerical example. Table 2 gives the optimal results for the proposed model.

Table 1. Input data for numerical example

\begin{tabular}{|c|c|c|c|c|c|}
\hline \multicolumn{3}{|c|}{ Retailer } & \multicolumn{3}{|c|}{ Manufacturer and 3PL } \\
\hline$i=$ & 1 & 2 & & & \\
\hline$\alpha_{i_{\text {max }}}^{\prime}$ & $28(\$ /$ item $)$ & $28(\$ /$ item $)$ & $\begin{array}{l}\mathrm{P}=10,000 \\
\text { (units/year) }\end{array}$ & $\begin{array}{l}h_{f}=5.2 \\
(\$ / \text { item/year })\end{array}$ & $\begin{array}{l}S=60 \\
(\$ / \text { order })\end{array}$ \\
\hline $\boldsymbol{h}_{\boldsymbol{i}}$ & $\begin{array}{l}8.2(\$ / \text { item/ } \\
\text { unit) }\end{array}$ & $\begin{array}{l}8.1 \text { (\$/item/ } \\
\text { unit) }\end{array}$ & $\begin{array}{l}C_{m}=150 \\
(\$ / \text { item })\end{array}$ & $\mu=20(\%)$ & $\gamma=3000(\$)$ \\
\hline$A_{i}$ & 39 (\$/item) & 63 (\$/item) & $\begin{array}{l}C_{q}=6 \\
(\$ / \text { item })\end{array}$ & $\begin{array}{l}C_{\alpha}=0.5 \\
(\$ / \text { con- } \\
\text { tainer/year })\end{array}$ & $\begin{array}{l}O_{m}=10 \\
(\$ / \text { item })\end{array}$ \\
\hline$l_{i}$ & 0.007 year & 0.008 year & $g=100(\$)$ & $\begin{array}{l}R_{c}=20 \\
(\$ / \text { item })\end{array}$ & $\begin{array}{l}h_{r}=5 \\
(\$ / \text { item/unit) }\end{array}$ \\
\hline$l_{i m}$ & $50(\mathrm{~km})$ & $40(\mathrm{~km})$ & $\begin{array}{l}C_{t}=0.01 \\
(\$ / \text { con- } \\
\text { tainer } / \mathrm{km})\end{array}$ & $\begin{array}{l}C_{3}=90 \\
\text { (\$/unit) }\end{array}$ & $\begin{array}{l}h_{u}=0.2 \\
(\$ / \text { item/unit })\end{array}$ \\
\hline$l_{i k}$ & $25(\mathrm{~km})$ & $25(\mathrm{~km})$ & $s=2$ & $\kappa=80(\%)$ & $\mathrm{e}=1.2(\$)$ \\
\hline $\boldsymbol{\alpha}_{i_{\text {min }}}^{\prime}$ & $5(\$ /$ item $)$ & $5(\$ /$ item $)$ & $\begin{array}{l}C_{r}=30 \\
(\$ / \text { item })\end{array}$ & $\begin{array}{l}l_{k m}=25 \\
(\mathrm{~km})\end{array}$ & $\delta=2$ \\
\hline$c_{i}$ & 9000 & 9720 & $\begin{array}{l}\alpha_{i_{\max }}=18 \\
(\$ / \text { item })\end{array}$ & $\begin{array}{l}\beta_{i_{\max }}=5 \\
(\$ / \text { item })\end{array}$ & $\begin{array}{l}\alpha_{i_{\min }}=4 \\
(\$ / \text { item })\end{array}$ \\
\hline$a_{i}$ & 0.0001 & 0.0081 & $\begin{array}{l}S_{3}=50 \\
(\$ / \text { order })\end{array}$ & $\begin{array}{l}D_{\max }= \\
4000 \\
\text { (units/year) }\end{array}$ & $\begin{array}{l}\beta_{i_{\min }}=1 \\
(\$ / \text { item })\end{array}$ \\
\hline
\end{tabular}

Table 2. Optimum results for the model

\begin{tabular}{|l|l|}
\hline Decision variables & Values \\
\hline $\boldsymbol{Z}^{*}$ (retailer) & $(2,1)$ \\
\hline $\boldsymbol{Q}^{*}$ (units) & 255.85 \\
\hline $\boldsymbol{\tau}^{*}$ (rate) & 0.11 \\
\hline $\boldsymbol{\varepsilon}^{*}$ (units) & 5 \\
\hline $\boldsymbol{\alpha}_{(\mathbf{1}, \mathbf{2},)}(\$)$ & $(4.1,4.2)$ \\
\hline $\boldsymbol{\alpha}_{(\mathbf{1}, \mathbf{2},)}^{\prime}(\$)$ & $(17.64,17.67)$ \\
\hline $\boldsymbol{\beta}_{(\mathbf{1}, \mathbf{2},)}(\$)$ & $(4.65,4.76)$ \\
\hline
\end{tabular}




\begin{tabular}{|l|l|}
\hline $\boldsymbol{\theta}_{(\mathbf{1}, \mathbf{2})}(\$)$ & $(0.83,0.11)$ \\
\hline $\boldsymbol{r}_{(\mathbf{1}, \mathbf{2})}$ (containers) & $(10,40)$ \\
\hline $\boldsymbol{q}^{*}{ }_{(\mathbf{1}, \mathbf{2})}$ (units) & $(54,201.85)$ \\
\hline $\boldsymbol{T P}\left(\mathbf{Z}^{*}, \boldsymbol{\alpha}^{*}{ }_{i}, \boldsymbol{\alpha}^{\prime *}{ }_{i}, \boldsymbol{\beta}^{*}{ }_{\boldsymbol{i}^{\prime}} \boldsymbol{\theta}^{*}{ }_{i}, \boldsymbol{q}^{*}{ }_{i}, \boldsymbol{\tau}, \boldsymbol{\varepsilon}\right)$ (\$/cycle) & 1868.55 \\
\hline
\end{tabular}

\subsection{Sensitivity Analysis}

From sensitivity analysis of Table 3 , it can be concluded that some costs have inverse impact on the total profit such that if related costs increase, total profit decreases and vice-versa. Such type of costs are service investments (e), setup cost (S), ordering cost $\left(O_{m}\right)$, finished products' holding cost $\left(h_{f}\right)$ and used products' holding cost $\left(h_{u}\right)$ of manufacturer, setup cost for 3PL $\left(S_{3}\right)$, ordering cost $\left(A_{1}\right.$, and $\left.A_{2}\right)$ and holding cost ( $h_{1}$ and $h_{2}$ ) of two retailers in which $A_{2}$ is most sensitive for retailers. Average recycling cost $\left(R_{c}\right)$ and transportation cost per container $\left(C_{t}\right)$ have direct impact on total profit whereas container managing cost $\left(C_{\alpha}\right)$ is the most sensitive for manufacturer followed by the container's holding cost $\left(h_{r}\right)$, which is the second most sensitive parameter for manufacturer.

Thus, whenever the third party logistic is involved in the SCM, industry manager needs to more careful about managing containers properly such that it can optimize holding cost because managing large size of containers is always a challenge for industry, otherwise it can create more lead time for shipments, which creates again holding cost issue for both finished products and used products. As recycling is better than holding those used products as long, according to sensitivity analysis, suggestion to industry manager is that investing on quick recycling rather than holding used products might be more profitable for industry.

Table 3. Sensitivity analysis of total profit for key parameters

\begin{tabular}{|c|c|c|c|c|c|}
\hline $\begin{array}{l}\text { Param- } \\
\text { eters }\end{array}$ & $\begin{array}{l}\text { Changes } \\
\text { in inputs } \\
\text { (in \%) }\end{array}$ & $\begin{array}{l}\text { Changes in } \\
\text { total profit } \\
\text { (in \%) }\end{array}$ & Parameters & $\begin{array}{l}\text { Changes in } \\
\text { inputs } \\
\text { (in) }\end{array}$ & $\begin{array}{l}\text { Changes in } \\
\text { total profit } \\
\text { (in \%) }\end{array}$ \\
\hline & -25 & +0.32 & & -25 & +0.13 \\
\hline $\mathrm{e}$ & -10 & +0.14 & $\mathrm{~S}$ & -10 & +0.05 \\
\hline & +10 & -0.16 & & +10 & -0.05 \\
\hline & +25 & -0.42 & & +25 & -0.13 \\
\hline & -25 & +0.05 & & -25 & +16.69 \\
\hline $\boldsymbol{S}_{\mathbf{3}}$ & -10 & +0.02 & $h_{f}$ & -10 & +6.68 \\
\hline & +10 & -0.02 & & +10 & -6.68 \\
\hline & +25 & -0.05 & & +25 & -16.69 \\
\hline & -25 & +0.20 & & -25 & +0.21 \\
\hline $\boldsymbol{h}_{\boldsymbol{u}}$ & -10 & +0.08 & $O_{m}$ & -10 & +0.09 \\
\hline & +10 & -0.08 & & +10 & -0.09 \\
\hline & +25 & -0.020 & & +25 & -0.21 \\
\hline & -25 & +3.03 & & -25 & +10.61 \\
\hline
\end{tabular}




\begin{tabular}{|c|c|c|c|c|c|}
\hline $\boldsymbol{A}_{\mathbf{1}}$ & -10 & +1.21 & $\boldsymbol{A}_{\mathbf{2}}$ & -10 & +4.25 \\
\hline & +10 & -1.21 & & +10 & -4.25 \\
\hline & +25 & -3.03 & & +25 & -10.61 \\
\hline & -25 & +0.05 & & -25 & +0.05 \\
\hline $\boldsymbol{h}_{\mathbf{1}}$ & -10 & +0.02 & $\boldsymbol{h}_{\mathbf{2}}$ & -10 & +0.02 \\
\hline & +10 & -0.02 & & +10 & -0.02 \\
\hline & +25 & -0.05 & & +25 & -0.05 \\
\hline & -25 & -40.95 & & -25 & -0.10 \\
\hline $\boldsymbol{R}_{\boldsymbol{c}}$ & -10 & -16.37 & $C_{t}$ & -10 & -0.04 \\
\hline & +10 & +16.36 & & +10 & +0.04 \\
\hline & +25 & +40.87 & & +25 & +0.10 \\
\hline & -25 & +670.10 & & -25 & +1675.22 \\
\hline $\boldsymbol{h}_{\boldsymbol{r}}$ & -10 & +268.04 & $C_{\alpha}$ & -10 & +670.10 \\
\hline & +10 & $\sim$ & & +10 & $\sim$ \\
\hline & +25 & $\sim$ & & +25 & $\sim$ \\
\hline
\end{tabular}

“ " stands for no feasible solution.

\section{Conclusions}

The main applicability of the model was to provide service to the industry and finally to customers. Due to always optimum service facility, customers would be benefitted. Due to the service from the third-party, the reused products could be used for remanufacturing and the manufacturing cost was reduced, which was the indicator of the reduced optimum selling prices of products. Thus, due to remanufacturing, the customer was being benefitted with more services. Numerical experiment proved that the industry obtained the optimum cost at the optimum service to the customer. The model did not consider about the defective products during collecting used products, which is quite natural in general, that is a limitation of the model as the rate of getting defective items may be random. This model can be extended by using service of 3PL and using imperfect production system and inspection.

\section{References}

1. Lee, J.: Inventory control by different service levels. Applied Mathematical Modelling 35, 497-505 (2011).

2. Krishnamoorthy, A., Viswanath, N.C.: Stochastic decomposition in production inventory with service time. European Journal of Operational Research 228, 358366 (2013).

3. Gzara, F., Nematollahi, E., Dasci, A.: Linear location-inventory models for service parts logistics network design. Computers \& Industrial Engineering 69, 5363 (2014).

4. Chen, X., Feng, Y., Keblis, M., Xu, J.: Optimal inventory policy for two substitutable products with customer service objectives. European Journal of Operational Research 246, 76-85 (2015). 
5. Wheatley, D., Gzara, F., Jewkes, E.: Logic-based Benders decomposition for an inventory-location problem with service constraints. Omega 55, 10-23 (2015).

6. Protopappa-Sieke, M., Sieke, M., Thonemamm, U.W.: Optimal two-period inventory allocation under multiple service level contracts. European Journal of Operational Research 252, 145-155 (2016).

7. Cordes, A-K., Hellingrath, B.: Master model for integrating inventory, transport and service personal capacity planning. International Federation of Automatic Control 49(30), 186-191 (2016).

8. Marand, A.J., Li, H., Thorstenson, A.: Joint inventory control and pricing in a service-inventory system. International Journal of Production Economics, https://doi.org/10.1016/j.ijpe.2017.07.008, (2017).

9. Rahimi, M., Baboli, A., Rekik, Y.: Multi-objective inventory routing problem: A stochastic model to consider profit, service level and green criteria. Transportation Research Part E 101, 59-83 (2017).

10. Aydinliyim, T., Pangburn, M., Rabinovich, E.: Inventory disclosure in online retailing. European Journal of Operational Research 261,195-204 (2017).

11. Transchel, S.: Inventory management under price-based and stockout-based substitution. European Journal of Operational Research 262, 996-1008 (2017).

12. Wu, J., Chang, C.-T., Teng, J.-T., Lai, K.-K.: Optimal order quantity and selling price over a product life cycle with deterioration rate linked to expiration date. International Journal of Production Economics 193, 343-351 (2017).

13. Chen, X.A., Wang, Z., Yuan, H.: Optimal pricing for selling to a static multiperiod newsvendor. Operations Research Letters 45, 415-420 (2017).

14. Rajesh, R., Pugazhendhi, S., Ganesh, K., Muralidharan, C., Sathiamoorthy, R.: Influence of 3PL service offerings on client performance in India. Transportation Research Part E 47, 149-165 (2011).

15. Li, F., Li, L., Jin, C., Wang, R., Wang, H., Yang, L.: A 3PL supplier selection model based on fuzzy sets. Computers \& Operations Research 39, 1879-1884 (2012).

16. Zhang, J., Nault, B.R., Tu, Y.: A dynamic pricing strategy for a 2PL provider with heterogeneous customers. International Journal of Production Economics 169, 3143 (2015).

17. Huo, B., Ye, Y., Zhao, X., Wei, J., Hua, Z.: Environmental uncertainty, specific assets, and opportunism in 3PL relationships: A transaction cost economics perspective. International Journal of Production Economics, 10.1016/ j.ijpe.2018.01.031, (2018).

18. Chung, W., Talluri, S., Kovács, G.: Investigating the effects of lead-time uncertainties and safety stocks on logistics performance in a border-crossing JIT supply chain. Computers \& Industrial Engineering 118, 440-450 (2018).

19. Glock, C.H., Kim, T.: Shipment consolidation in a multiple-vendor-single-buyer integrated inventory model. Computers \& Industrial Engineering 70, 31-42 (2014).

20. Sarkar, B., Ullah, M., Kim, N.: Environmental and economic assessment of closed-loop supply chain with remanufacturing and returnable transport items. Computers \& Industrial Engineering 111, 148-163 (2017). 